Article

\title{
The Effectiveness of Botulinum Toxin Type A (BoNT-A) Treatment in Brazilian Patients with Chronic Post-Stroke Spasticity: Results from the Observational, Multicenter, Prospective BCause Study
}

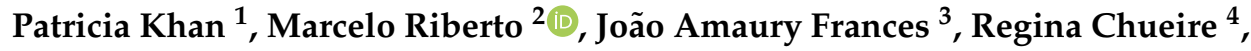 \\ Ana Cristina Ferreira Garcia Amorim ${ }^{5}$, Denise Xerez ${ }^{6}$, Tae Mo Chung ${ }^{7}$, \\ Lucia Helena Costa Mercuri ${ }^{8}$, Alexandre Luiz Longo ${ }^{9}$, Sérgio Lianza ${ }^{10}$, Pascal Maisonobe ${ }^{11, *}$ \\ and Viviane C. Ruiz-Schutz ${ }^{12}$ \\ Centro Catarinense de Reabilitação, Florianópolis, Santa Catarina 88025-301, Brazil; patskh@yahoo.com \\ 2 Faculdade de Medicina de Ribeirão Preto, Universidade de São Paulo, Ribeirão Preto, São Paulo 14049-900, \\ Brazil; mriberto@usp.br \\ 3 Hospital Bettina Ferro de Souza, Campus IV da Universidade Federal do Pará, Belém, Pará 66075-110, Brazil; \\ amaury.frances@yahoo.com.br \\ 4 Faculdade de Medicina de São José do Rio Preto, Autarquia Estadual, São José do Rio Preto 15090-000, Brazil; \\ reginahelena.reginahelena@gmail.com \\ 5 Centro de Reabilitação e Readaptação Dr. Henrique Santillo (CRER), Goiânia, Goiás 74653-230, Brazil; \\ anafisiatra@gmail.com \\ 6 Serviço de Medicina Física e Reabilitação, Hospital Universitário Clementino Fraga Filho, Universidade \\ Federal do Rio de Janeiro, Rio de Janeiro 21941-590, Brazil; drxerez@gmail.com \\ 7 Instituto de Medicina Física e Reabilitação, Hospital das Clínicas da Faculdade de Medicina da Universidade \\ de São Paulo, São Paulo 04116-030, Brazil; taemochung@gmail.com \\ 8 Hospital São Paulo-UNIFESP, São Paulo 04024-002, Brazil; lumercuri1@gmail.com \\ 9 Clinica Neurológica e Neurocirúrgica de Joinville, Joinville, Santa Catarina 89202-165, Brazil; \\ alexandrellongo@gmail.com \\ 10 Hospital Alemão Oswaldo Cruz, São Paulo 01323-020, Brazil; sergiol@uol.com.br \\ 11 Ipsen, 92100 Boulogne Billancourt, France \\ 12 Ipsen, São Paulo 04571-010, Brazil; viviane.ruiz@ipsen.com \\ * Correspondence: pascal.maisonobe@ipsen.com
}

Received: 9 November 2020; Accepted: 25 November 2020; Published: 4 December 2020

\begin{abstract}
Botulinum toxin type A (BoNT-A) is an effective treatment for post-stroke spasticity; however, some patients cannot access treatment until $\geq 1$ year post-stroke. This Brazilian post-marketing study (NCT02390206) assessed the achievement of person-centered goals in patients with chronic post-stroke spasticity after a BoNT-A injection. Patients had a last documented stroke $\geq 1$ year before study entry and post-stroke upper limb (UL) spasticity, with or without lower limb (LL) spasticity. Patients received BoNT-A injections at baseline (visit 1) and visit 2 (3-6 months). Primary endpoint was responder rate (achievement of primary goal from Goal Attainment Scaling (GAS)) at visit 2. Overall, 204 patients underwent GAS evaluation at visit 2, mean (SD) age was 56.4 (13.2) years and $90.7 \%$ had LL spasticity. Median (range) time between first stroke and onset of spasticity was $3.6(0-349)$ months, onset of spasticity and first injection was $22.7(0-350)$ months and waiting time for a rehabilitation appointment was 9.0 (1-96) months. At visit 2, 61.3\% (95\% CI: 54.4, 67.7) of patients were responders, which was similar for UL and LL primary goals (57.8\% [95\% CI: 49.9, 65.3] vs. 64.1\% [95\% CI: 48.4, 77.3]). This study provides evidence to support the effectiveness of BoNT-A treatment for chronic post-stroke spasticity.
\end{abstract}


Keywords: spasticity; stroke; pain; quality of life

Key Contribution: The results from this study demonstrate that over half of patients with chronic post-stroke spasticity, in both upper and lower limb, respond to a single botulinum toxin type A injection. This finding suggests that in countries where early post-stroke spasticity treatment is not always possible, patients can still benefit from BoNT-A treatment.

\section{Introduction}

Post-stroke spasticity has been reported to occur in $17-38 \%$ of stroke cases [1-3]. Botulinum toxin type A (BoNT-A) injections are a known effective treatment for spasticity and are often recommended in clinical practice [4-6]. Studies have shown that the use of BoNT-A in the treatment of upper limb (UL) and lower limb (LL) spasticity reduces muscle tone and spasticity symptoms, and improves range of motion (ROM) and functions such as walking speed [7-11]. These physical improvements may enhance the patient's quality of life (QoL) and reduce the perceived burden on caregivers. BoNT-A products are approved for the treatment of UL and LL spasticity in adults in a number of countries worldwide; in Brazil, the first marketing authorization was granted for onabotulinumtoxinA in 2000 [12]. Treatment with BoNT-A is often deferred until the patient shows clinical signs of spasticity, usually at least 3 months post-stroke [13]. However, recent studies have demonstrated that treatment with BoNT-A as early as $2-12$ weeks following stroke may prevent the development of spasticity and improve muscle tone, thus improving prognosis [13-16].

Although standard practice and treatment guidelines recommend that rehabilitation programs start early in the management of post-stroke spasticity [6], in many low- and middle-income countries this approach is not possible. A lack of rehabilitation in the standard of care, inadequate physician knowledge of the role of rehabilitation, and poor public insurance or financial support, among other contextual factors, are barriers to patients accessing treatment [17]. Consequently, many patients with post-stroke spasticity only receive rehabilitation treatment and BoNT-A in the chronic phase (more than 1 year post-stroke). In clinical practice, there are few studies directly investigating the effectiveness of BoNT-A when first administered during chronic spasticity; therefore, it is not clear whether late administration is effective at reducing disease burden.

The BCause study (Botulinum toxin in the treatment of Chronic post-stroke spAStic patiEnts; NCT02390206) evaluated the achievement of individual person-centered goals, using Goal Attainment Scaling (GAS) [18]. after treatment with BoNT-A injections in Brazilian patients with untreated chronic post-stroke spasticity. The study also aimed to document the time between the onset of spasticity and access to treatment, the sociodemographic profile of the patients, and the standard of care, to identify potential barriers responsible for the delay in receiving adequate treatment.

\section{Results}

\subsection{Study Population}

A total of 239 patients were enrolled in the study (Figure 1); of the 234 patients who received treatment, 30 did not undergo GAS evaluation at visit 2 (FAS: $n=204$ ) and 181 patients completed the study. There were no major protocol deviations/violations in the study.

Participants' baseline characteristics are reported in Table 1. The mean (standard deviation (SD)) age of patients was 56.4 (13.2) years, $51.5 \%$ were male, and $77.9 \%$ of patients had experienced only one stroke episode. Patients had a median (range) of 3.6 months (0-349) between their first stroke and onset of spasticity, and over $90 \%$ of patients were also affected by spasticity in the LL. The median (range) time between the onset of spasticity and first BoNT-A injection at baseline was $22.7(0-350)$ months. 


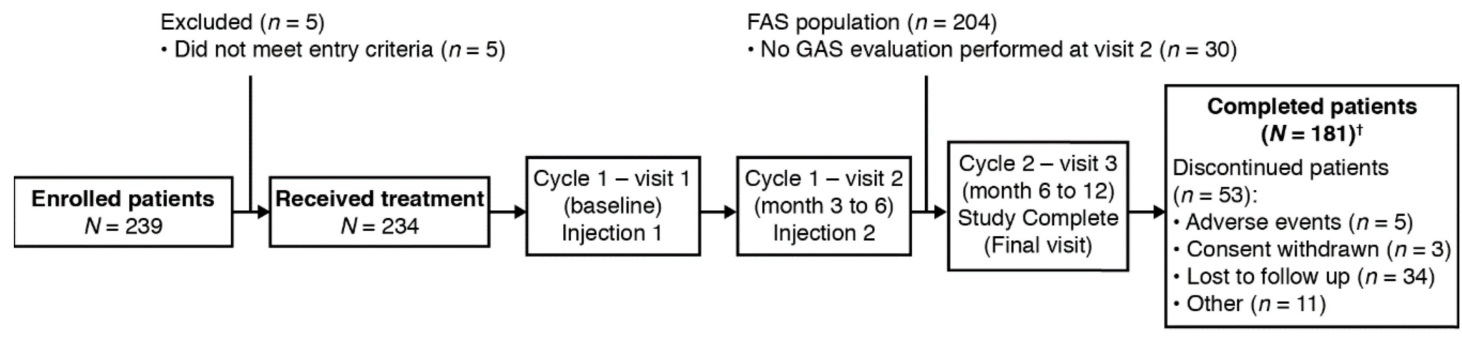

Figure 1. Study design and patient disposition. ${ }^{\dagger}$ One patient who completed the study and attended visit 3 was not included in the FAS population. FAS, full analysis set; GAS, goal attainment scaling.

Table 1. Baseline characteristics in patients with chronic post-stroke spasticity (FAS). ${ }^{+}$The denominator of percentage is the number of patients with affected limbs. Percentages are based on the number of non-missing observations in the FAS. CVA, cerebrovascular accident; FAS, full analysis set; LL, lower limb; SD, standard deviation; UL, upper limb.

\begin{tabular}{|c|c|}
\hline Parameter & $\begin{array}{l}\text { All Patients } \\
\quad(n=204)\end{array}$ \\
\hline Age in years, mean (SD); median [range] & $56.4(13.2) ; 59.0$ [18-79] \\
\hline $\begin{array}{l}\text { Sex, } n(\%) \\
\quad \text { Male } \\
\text { Female }\end{array}$ & $\begin{array}{l}105(51.5) \\
99(48.5)\end{array}$ \\
\hline $\begin{array}{l}\text { Handedness, } n(\%) \\
\text { Ambidextrous } \\
\text { Left } \\
\text { Right }\end{array}$ & $\begin{array}{c}4(2.0) \\
14(6.9) \\
186(91.2)\end{array}$ \\
\hline Time since last CVA (months), mean (SD); median [range] & $51.3(61.4) ; 28.1[12-374]$ \\
\hline $\begin{array}{c}\text { Etiology of last CVA, } n(\%) \\
\text { Hemorrhage } \\
\text { Infarct } \\
\text { Infarct and hemorrhage }\end{array}$ & $\begin{array}{c}45(22.1) \\
151(74.0) \\
8(3.9)\end{array}$ \\
\hline $\begin{array}{l}\text { Location of last CVA, } n(\%) \\
\text { Left hemisphere } \\
\text { Posterior circulation } \\
\text { Right hemisphere }\end{array}$ & $\begin{array}{c}99(48.5) \\
3(1.5) \\
102(50.0)\end{array}$ \\
\hline $\begin{array}{c}\text { Number of CVA episodes (previous and studied), } n(\%) \\
1 \\
2 \\
3 \\
>3\end{array}$ & $\begin{array}{c}159(77.9) \\
32(15.7) \\
8(3.9) \\
5(2.5)\end{array}$ \\
\hline Time since onset of stroke (months), mean (SD); median [range] & $61.6(69.4) ; 32.0$ [12-374] \\
\hline Time since onset of spasticity (months), mean (SD); median [range] & $40.2(53.1) ; 22.7[0-350]$ \\
\hline $\begin{array}{l}\text { Time between first CVA and onset of spasticity (months), } \\
\text { mean (SD); median [range] }\end{array}$ & $25.7(53.2) ; 3.6[0-349]$ \\
\hline $\begin{array}{c}\text { UL affected by spasticity, } n(\%) \\
\text { Right } \\
\text { Left } \\
\text { Bilateral }\end{array}$ & $\begin{array}{c}204(100) \\
93(45.6) \\
105(51.5) \\
6(2.9)\end{array}$ \\
\hline $\begin{array}{c}\text { LL affected by spasticity, } n(\%) \\
\text { Right } \\
\text { Left } \\
\text { Bilateral }\end{array}$ & $\begin{array}{c}185(90.7) \\
84(45.4) \\
95(51.4) \\
6(3.2)\end{array}$ \\
\hline
\end{tabular}


Table 1. Cont.

\begin{tabular}{|c|c|}
\hline Parameter & $\begin{array}{l}\text { All Patients } \\
\quad(n=204)\end{array}$ \\
\hline $\begin{array}{c}\text { UL spasticity patterns, } n(\%)^{\dagger} \\
\text { Adducted internally rotated shoulder } \\
\text { Flexed elbow } \\
\text { Flexed wrist } \\
\text { Pronated forearm } \\
\text { Clenched fist } \\
\text { Thumb-in-palm }\end{array}$ & $\begin{array}{l}169(82.8) \\
168(82.4) \\
144(70.6) \\
133(65.2) \\
113(55.4) \\
101(49.5)\end{array}$ \\
\hline $\begin{array}{c}\text { LL spasticity patterns, } n(\%)^{\dagger} \\
\text { Equinovarus foot } \\
\text { Knee extension } \\
\text { Claw toes } \\
\text { Knee flexion } \\
\text { Hip adduction } \\
\text { Hip flexion } \\
\text { Striatal toe }\end{array}$ & $\begin{array}{l}147(79.5) \\
89(48.1) \\
70(37.8) \\
52(28.1) \\
36(19.5) \\
31(16.8) \\
23(12.4)\end{array}$ \\
\hline
\end{tabular}

Post-stroke complications were common in patients prior to entry into the study, with most $(73.0 \% ; n=149)$ experiencing at least one complication. Common post-stroke complications included hypertension $(53.0 \% ; n=79)$, depression/anxiety $(47.7 \% ; n=71)$, and aphasia $(34.9 \% ; n=52)$, which were ongoing at baseline in $98.7 \%(n=78 / 79), 88.7 \%(n=63 / 71)$ and $59.6 \%(n=31 / 52)$ of patients, respectively.

In total, 25 patients (12.3\%) reported using concomitant medications, of whom $19(76.0 \%)$ used baclofen and $171(83.8 \%)$ reported using at least one concomitant non-drug therapy, with 140 patients (77.3\%) receiving physical therapy (Figure S1).

\subsection{Primary Efficacy Endpoint}

At visit 2, 125 patients $(61.3 \%$; 95\% CI: 54.4, 67.7) achieved their primary goal and were considered responders (Table 2), which is above the proportion expected in the sample size calculation. For those patients who set an UL primary goal, $57.8 \%$ (95\% CI: 49.9, 65.3) were responders compared with $64.1 \%$ (95\% CI: 48.4, 77.3) who set a LL primary goal.

Table 2. Primary efficacy endpoint (FAS). A responder was defined as a patient who achieved or overachieved the primary goal (goal rating of $0,+1$, or +2 ). The response after the first injection cycle was assessed at visit 2. Percentages are based on the number of patients with primary goal as applicable for the different limbs. FAS, full analysis set; LL, lower limb; n, number of patients; UL, upper limb.

\begin{tabular}{ccc}
\hline Visit $\mathbf{2}$ & $\boldsymbol{n} \mathbf{( \% )}$ & $\mathbf{9 5 \%} \mathbf{C I}$ \\
\hline Primary goal limb & & \\
UL $(n=154)$ & $89(57.8)$ & $49.9,65.3$ \\
LL $(n=39)$ & $25(64.1)$ & $48.4,77.3$ \\
Both limbs $(n=11)$ & $11(100.0)$ & $70.0,100.0$ \\
Overall $(n=204)$ & $125(61.3)$ & $54.4,67.7$ \\
\hline
\end{tabular}

\subsection{Secondary Effectiveness Endpoints}

\subsubsection{Responders at Visit 3}

In total, 180 patients (88.2\%) attended visit 3 , with $56.7 \%$ of patients responding to treatment (95\% CI: 49.4, 63.8; $n=101 / 178)$; the proportion of responders was similar in those who set UL and LL primary goals, $57.3 \%$ (95\% CI: $49.1,65.2 ; n=82 / 143)$ and $53.1 \%$ (95\% CI: $36.4,69.1 ; n=17 / 32)$, respectively. Of the three patients who set a primary goal in both limbs, two were responders $(66.7 \%$; $95 \%$ CI: $20.2,94.4 ; n=2 / 3)$. 


\subsubsection{GAS T Score}

GAS T scores increased during cycles 1 and 2 in patients injected in the UL, the LL, and in patients injected in both limbs (Figure 2). The mean (SD) overall cumulated GAS T score across both cycles was $48.24(8.18 ; n=191)$ in patients injected in the UL, $47.17(6.92 ; n=123)$ in patients injected in the LL, and $56.81(8.13 ; n=18)$ in patients injected in both the UL and LL.

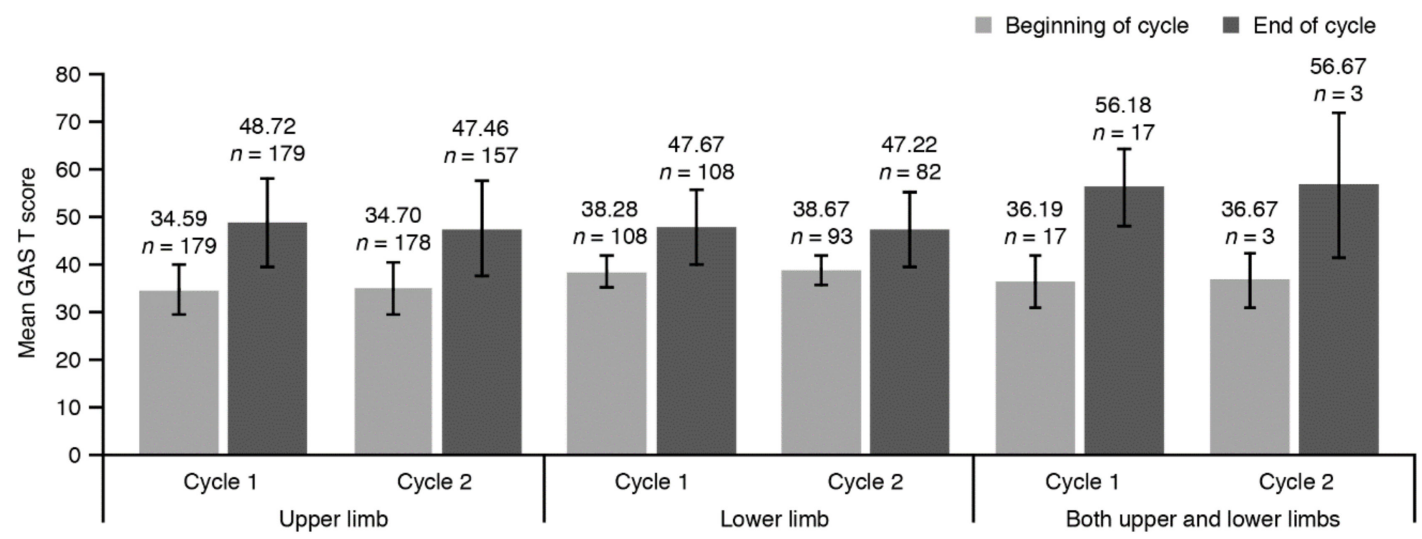

Figure 2. Mean GAS T score during cycles 1 and 2 according to injected limb (FAS). Error bars represent SD. Means are based on the number of non-missing observations in the FAS at the concerned time points. GAS, Goal Attainment Scale; FAS, full analysis set; $n$, number of patients; SD, standard deviation.

\subsubsection{Pain Scores}

Patients reported their pain scores using a VNS at each visit; at baseline, mean (SD) pain scores were higher at movement than at rest for UL (4.2 [3.8]; $n=194$ vs. 1.7 [3.1]; $n=193$, respectively) and LL (2.7 [3.5]; $n=173$ vs. 1.3 [2.7]; $n=172$, respectively).

At rest, there was very little change in the mean (SD) pain score in patients injected in the UL from baseline to visit $2(-0.5$ [2.9]; $n=193)$ and from baseline to visit $3(-0.5[2.9], n=170)$. The mean pain score for patients injected in the LL remained stable from baseline to visit $2(-0.1$ [2.7]; $n=170)$ and from baseline to visit $3(-0.1$ [3.0]; $n=149)$.

At movement, the mean (SD) pain score decreased throughout the study in patients injected in the UL, decreasing by -1.4 (3.4) from baseline to visit $2(n=194)$ and by -1.7 (3.4) from baseline to visit $3(n=171)$. In patients injected in the LL, there was very little change in the mean (SD) pain score from baseline to visit $2(-0.6[3.5] ; n=170)$ and baseline to visit $3(-0.5[3.5] ; n=150)$.

\subsubsection{Range of Motion}

Mean (SD) shoulder abduction angle increased throughout the study, increasing by $15.0^{\circ}(23.0)$ from baseline to visit $2(n=150)$ and by $21.6^{\circ}(28.6)$ from baseline to visit $3(n=129)$.

\subsubsection{MAS Spasticity Scores}

The mean MAS scores decreased slightly throughout the study. In the UL, the mean (SD) score decreased by $-0.30(0.50)$ from baseline to visit 2 and by $-0.40(0.56)$ from baseline to visit 3 , and in the LL decreased by $-0.14(0.54)$ and by -0.28 (0.59), respectively. Overall, mean (SD) MAS score decreased $-0.22(0.43)$ from baseline to visit 2 and by $-0.34(0.48)$ from baseline to visit 3 . There was a trend toward a decrease of the MAS score in each UL joint (shoulder, elbow, wrist, finger and thumb) and LL joint (hip, knee, ankle, and toe; Table S1). 


\subsubsection{Functional Independence}

The mean (SD) Barthel Index score increased during cycle 1, from $63.1(28.5 ; n=204)$ to $70.8(27.3$; $n=180)$ with a mean (SD) change of $5.1(12.3$; range: -35 to +50$)$. The proportion of patients who were independent at visit 3 increased compared with baseline for various activities of daily living (Table S2).

Using the FAC classification, the proportion of patients classified as non-functional decreased throughout the study: $22.2 \%$ at baseline, $17.2 \%$ at visit 2 and $15.9 \%$ at visit 3 (Figure 3). Conversely, the proportion of independent patients increased throughout the study: $22.8 \%$ at baseline, $31.7 \%$ at visit 2 and $38.9 \%$ at visit 3 .

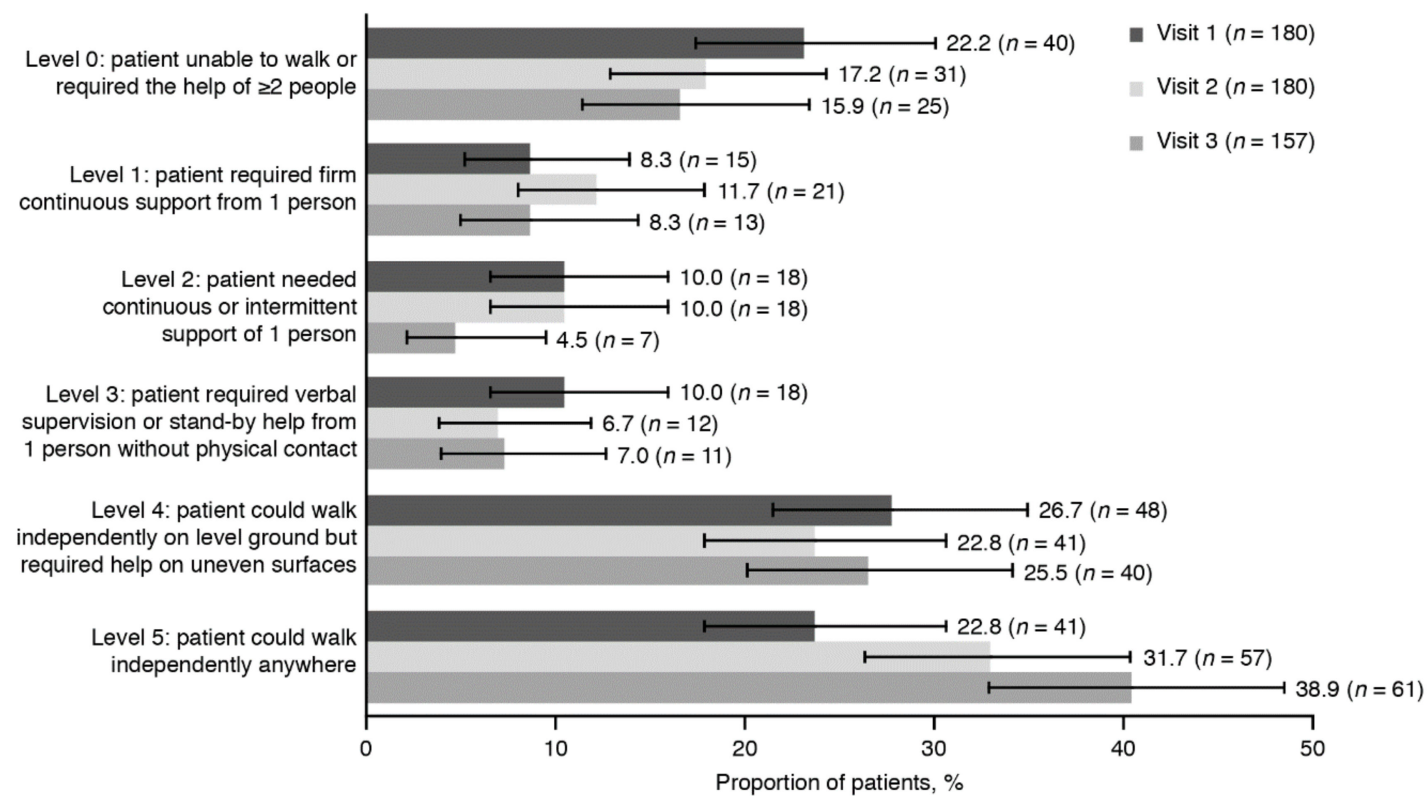

Figure 3. Functional independence according to the FAC classification at visits 1, 2 and 3 (FAS). Error bars represent $95 \%$ CI. Percentages are based on the number of non-missing observations in the FAS, data for 24 patients were missing for visits 1 and 2, and data for 47 patients were missing for visit 3 . Level 0, non-functional; level 1, dependent level II; level 2, dependent level I; level 3, dependent on supervision; level 4, independent on level ground; level 5, independent. CI, confidence interval; FAC, Functional Ambulation Category; FAS, full analysis set.

\subsubsection{QoL and Satisfaction}

The mean (SD) EQ VAS score increased throughout the study: from $61.8(24.3 ; n=137)$ at baseline to $66.6(21.6 ; n=127)$ at visit 2 and $69.5(20.8 ; n=113)$ at visit 3 . The proportion of patients with no problems in walking, washing, or dressing themselves, and doing their usual activities also increased during the study (Table 3), while the proportion of patients with moderate, severe, or extreme pain or discomfort decreased throughout the study. 
Table 3. Frequency of reported problems in the five domains of the EQ-5D-5L (FAS). Percentages are based on the number of non-missing observations in the FAS. CI, confidence interval; EQ-5D-5L, European Quality of Life-5 Dimensions-5 Levels; FAS, full analysis set; $n$, number of patients.

\begin{tabular}{|c|c|c|c|c|}
\hline Domain & Level & $\begin{array}{l}\text { Visit 1, } n(\%) \\
\quad[95 \% \mathrm{CI}]\end{array}$ & $\begin{array}{l}\text { Visit } 2, n(\%) \\
{[95 \% \mathrm{CI}]}\end{array}$ & $\begin{array}{l}\text { Visit 3, } n(\%) \\
\quad[95 \% \mathrm{CI}]\end{array}$ \\
\hline \multirow{6}{*}{ Mobility } & $\begin{array}{l}\text { I have no problem in } \\
\text { walking about }\end{array}$ & $7(5.1)[2.3,10.4]$ & $13(10.2)[6.0,16.9]$ & $17(15.0)[9.5,22.9]$ \\
\hline & $\begin{array}{l}\text { I have slight problems in } \\
\text { walking about }\end{array}$ & $35(25.5)[19.0,33.5]$ & $39(30.7)[23.3,39.2]$ & 40 (35.4) $[27.2,44.6]$ \\
\hline & $\begin{array}{l}\text { I have moderate problems in } \\
\text { walking about }\end{array}$ & 38 (27.7) $[20.9,35.8]$ & $38(29.9)[22.6,38.4]$ & $32(28.3)[20.8,37.3]$ \\
\hline & $\begin{array}{c}\text { I have severe problems in } \\
\text { walking about }\end{array}$ & $36(26.3)[19.6,34.2]$ & $19(15.0)[9.7,22.3]$ & $9(8.0)[4.1,14.6]$ \\
\hline & I am unable to walk about & $21(15.3)[10.2,22.4]$ & $18(14.2)[9.1,21.4]$ & 15 (13.3) [8.1, 20.9] \\
\hline & Missing & 67 & 77 & 91 \\
\hline \multirow{6}{*}{ Self-care } & $\begin{array}{l}\text { I have no problem washing } \\
\text { or dressing myself }\end{array}$ & $25(18.2)[12.6,25.6]$ & $34(26.8)[19.8,35.1]$ & $45(39.8)[31.3,49.0]$ \\
\hline & $\begin{array}{l}\text { I have slight problems } \\
\text { washing or dressing myself }\end{array}$ & 31 (22.6) $[16.4,30.4]$ & $32(25.2)[18.4,33.4]$ & $23(20.4)[13.9,28.8]$ \\
\hline & $\begin{array}{l}\text { I have moderate problems } \\
\text { washing or dressing myself }\end{array}$ & $29(21.2)[15.1,28.8]$ & $30(23.6)[17.0,31.8]$ & 25 (22.1) [15.4, 30.7] \\
\hline & $\begin{array}{c}\text { I have severe problems } \\
\text { washing or dressing myself }\end{array}$ & $17(12.4)[7.8,19.1]$ & $11(8.7)[4.8,15.0]$ & $10(8.8)[4.7,15.7]$ \\
\hline & $\begin{array}{l}\text { I am unable to wash or dress } \\
\text { myself }\end{array}$ & 35 (25.5) [19.0, 33.5] & $20(15.7)[10.4,23.2]$ & $10(8.8)[4.7,15.7]$ \\
\hline & Missing & 67 & 77 & 91 \\
\hline \multirow{6}{*}{ Usual activity } & $\begin{array}{l}\text { I have no problems doing } \\
\text { my usual activities }\end{array}$ & $9(6.6)[3.4,12.3]$ & $15(11.8)[7.2,18.7]$ & $21(18.6)[12.4,26.8]$ \\
\hline & $\begin{array}{l}\text { I have slight problems doing } \\
\text { my usual activities }\end{array}$ & $22(16.2)[10.9,23.3]$ & $36(28.3)[21.2,36.8]$ & $34(30.1)[22.4,39.1]$ \\
\hline & $\begin{array}{l}\text { I have moderate problems } \\
\text { doing my usual activities }\end{array}$ & 38 (27.9) [21.1, 36.0] & $34(26.8)[19.8,35.1]$ & $23(20.4)[13.9,28.8]$ \\
\hline & $\begin{array}{l}\text { I have severe problems } \\
\text { doing my usual activities }\end{array}$ & $28(20.6)[14.6,28.2]$ & $16(12.6)[7.8,19.6]$ & $17(15.0)[9.5,22.9]$ \\
\hline & $\begin{array}{l}\text { I am unable to do my usual } \\
\text { activities }\end{array}$ & $39(28.7)[21.7,36.8]$ & $26(20.5)[14.3,28.4]$ & 18 (15.9) [10.2, 23.9] \\
\hline & Missing & 68 & 77 & 91 \\
\hline \multirow{6}{*}{ Pain/discomfort } & I have no pain or discomfort & $40(29.2)[22.2,37.2]$ & $47(37.0)[29.1,45.7]$ & $53(46.9)[38.0,56.1]$ \\
\hline & $\begin{array}{l}\text { I have slight pain } \\
\text { or discomfort }\end{array}$ & $35(25.5)[19.0,33.5]$ & $41(32.3)[24.8,40.8]$ & 32 (28.3) [20.8, 37.3] \\
\hline & $\begin{array}{l}\text { I have moderate pain } \\
\text { or discomfort }\end{array}$ & $34(24.8)[18.3,32.7]$ & $24(18.9)[13.0,26.6]$ & $18(15.9)[10.2,23.9]$ \\
\hline & $\begin{array}{l}\text { I have severe pain } \\
\text { or discomfort }\end{array}$ & $20(14.6)[9.6,21.6]$ & $13(10.2)[6.0,16.9]$ & $9(8.0)[4.1,14.6]$ \\
\hline & $\begin{array}{l}\text { I am extreme pain } \\
\text { or discomfort }\end{array}$ & $8(5.8)[2.8,11.3]$ & $2(1.6)[0.1,5.9]$ & $1(0.9)[0.0,5.3]$ \\
\hline & Missing & 67 & 77 & 91 \\
\hline
\end{tabular}


Table 3. Cont.

\begin{tabular}{|c|c|c|c|c|}
\hline Domain & Level & $\begin{array}{l}\text { Visit } 1, n(\%) \\
{[95 \% \mathrm{CI}]}\end{array}$ & $\begin{array}{l}\text { Visit } 2, n(\%) \\
\quad[95 \% \mathrm{CI}]\end{array}$ & $\begin{array}{l}\text { Visit 3, } n(\%) \\
{[95 \% \mathrm{CI}]}\end{array}$ \\
\hline \multirow{6}{*}{ Anxiety/depression } & $\begin{array}{c}\text { I am not anxious or } \\
\text { depressed }\end{array}$ & $47(34.3)[26.9,42.6]$ & $39(30.7)[23.3,39.2]$ & $43(38.1)[29.6,47.3]$ \\
\hline & $\begin{array}{l}\text { I am slightly anxious } \\
\text { or depressed }\end{array}$ & $36(26.3)[19.6,34.2]$ & $38(29.9)[22.6,38.4]$ & $36(31.9)[24.0,40.9]$ \\
\hline & $\begin{array}{c}\text { I am moderately anxious } \\
\text { or depressed }\end{array}$ & $30(21.9)[15.8,29.6]$ & $32(25.2)[18.4,33.4]$ & $21(18.6)[12.4,26.8]$ \\
\hline & $\begin{array}{c}\text { I am severely anxious } \\
\text { or depressed }\end{array}$ & $10(7.3)[3.9,13.1]$ & $12(9.4)[5.4,15.9]$ & $10(8.8)[4.7,15.7]$ \\
\hline & $\begin{array}{c}\text { I am extremely anxious } \\
\text { or depressed }\end{array}$ & $14(10.2)[6.1,16.5]$ & $6(4.7)[2.0,10.1]$ & $3(2.7)[0.6,7.9]$ \\
\hline & Missing & 67 & 77 & 91 \\
\hline
\end{tabular}

Investigators, patients, and caregivers also reported on their satisfaction regarding treatment effectiveness, with over $70 \%$ of respondents reporting that treatment with BoNT-A provided a great, or some, benefit across cycles 1 and 2 (Table 4).

Table 4. Satisfaction regarding treatment effectiveness according to investigators, patients, and caregivers (FAS). Percentages are based on the number of non-missing observations in the FAS. CI, confidence interval; FAS, full analysis set; $n$, number of patients.

\begin{tabular}{ccccc}
\hline \multirow{2}{*}{ Visit } & $\begin{array}{c}\text { Treatment } \\
\text { Satisfaction }\end{array}$ & $\begin{array}{c}\text { Investigators' Global } \\
\text { Assessment of Benefit, } \\
\boldsymbol{n} \mathbf{( \% )}[\mathbf{9 5 \%} \mathbf{C I}]\end{array}$ & $\begin{array}{c}\text { Patients' Global } \\
\text { Assessment of Benefit, } \\
\boldsymbol{n} \mathbf{( \% )}[\mathbf{9 5} \% \mathbf{C I}]\end{array}$ & $\begin{array}{c}\text { Caregivers' Global } \\
\text { Assessment of Benefit, } \\
\boldsymbol{n} \mathbf{( \% )}[\mathbf{9 5 \%} \text { CI] }\end{array}$ \\
\hline End of cycle 1 & Great benefit & $61(29.9)[24.0,36.5]$ & $81(39.7)[33.2,46.6]$ & $72(35.3)[29.1,42.1]$ \\
& Some benefit & $135(66.2)[59.4,72.3]$ & $92(45.1)[38.4,52.0]$ & $80(39.2)[32.8,46.1]$ \\
& Same & $7(3.4)[1.5,7.0]$ & $22(10.8)[7.2,15.8]$ & $16(7.8)[4.8,12.4]$ \\
& Worse & $0(0)[0.0,2.2]$ & $2(1.0)[0.0,3.7]$ & $0(0)[0.0,2.2]$ \\
& Much worse & $1(0.5)[0.0,3.0]$ & $0(0)[0.0,2.2]$ & $0(0)[0.0,2.2]$ \\
& Not done & $0(0)[0.0,2.2]$ & $7(3.4)[1.5,7.0]$ & $36(17.6)[13.0,23.5]$ \\
& Missing & 0 & 0 & 0 \\
& Great benefit & $67(37.2)[30.5,44.5]$ & $79(43.9)[36.8,51.2]$ & $65(36.1)[29.4,43.4]$ \\
& Some benefit & $102(56.7)[49.4,63.7]$ & $72(40.0)[33.1,47.3]$ & $64(35.6)[28.9,42.8]$ \\
& Same & $7(3.9)[1.7,8.0]$ & $19(10.6)[6.8,16.0]$ & $12(6.7)[3.7,11.4]$ \\
& Worse & $4(2.2)[0.7,5.8]$ & $2(1.1)[0.0,4.2]$ & $1(0.6)[0.0,3.4]$ \\
& Much worse & $0(0)[0.0,2.5]$ & $1(0.6)[0.0,3.4]$ & $0(0)[0.0,2.5]$ \\
& Not done & $0(0)[0.0,2.5]$ & $7(3.9)[1.7,8.0]$ & $38(21.1)[15.8,27.7]$ \\
& Missing & 24 & 24 & 24 \\
\hline
\end{tabular}

\subsection{Socio-Demographic Data}

Of the 204 patients included in the FAS, 203 patients provided data on their education history. The majority of patients had attended school $(93.1 \% ; n=189)$, with a median (range) number of years spent attending school of 6.0 (1-18) years, and 24 patients $(11.8 \%)$ had attended university. The professional status was known for 201 patients: 106 (52.7\%) were retired, $71(35.3 \%)$ received social benefits, 11 (5.5\%) were unemployed, 8 (4.0\%) had never worked, and 5 (2.5\%) were employed. The patients' working status was a consequence of stroke in $63.8 \%$ of cases $(n=120 / 188)$. The majority of patients in the study had public health insurance $(90.7 \% ; n=185)$ compared with private health insurance $(9.3 \% ; n=19)$.

The most frequent reasons that patients reported for not undergoing earlier rehabilitation were either because rehabilitation was only indicated/prescribed recently $(44.6 \% ; n=91)$, or because they were unable to schedule an appointment for rehabilitation $(16.2 \% ; n=33)$. The median (range) waiting time for an appointment at a center was 9.0 (1-96) months. Patients reported a number of factors that 
made access to treatment difficult (Figure 4), of which the most common was distance or transportation to the outpatient center (32.8\%). The median (range) time for travel to a center was 60.0 (5-240) $\mathrm{min}$.

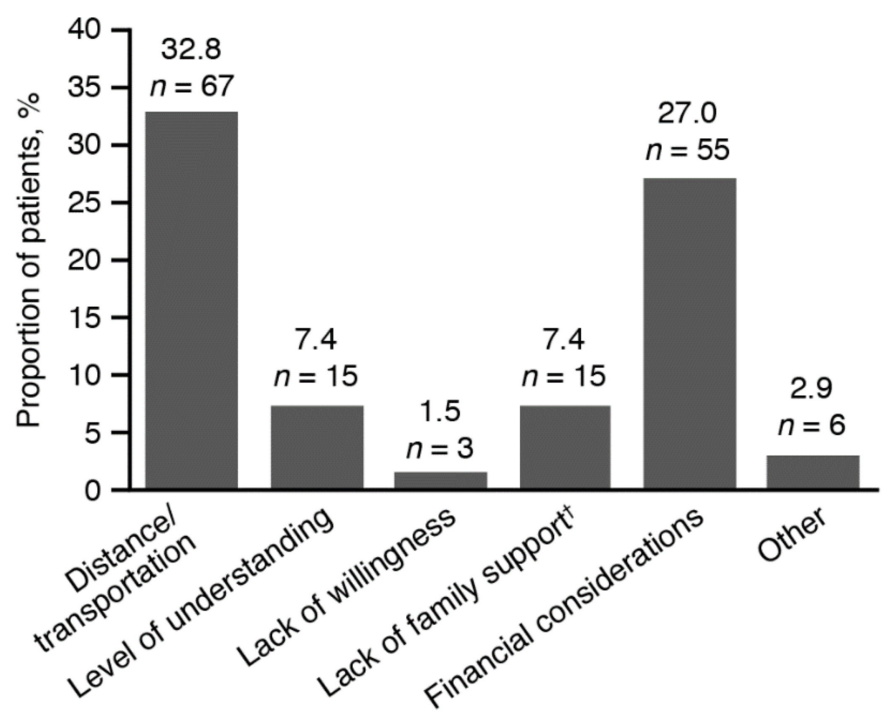

Figure 4. Factors that made receiving treatment difficult for patients (FAS) ${ }^{\dagger}$ Lack of family support includes having no relative to accompany the patient to appointments. The denominator of percentage is the number of subjects in the FAS. Data for 98 (48.0\%) patients in the FAS were missing; the sum of percentages may exceed $100 \%$. FAS, full analysis set.

\subsection{Injection Practices}

Of the 204 patients injected at visit 1 and the 201 patients injected at visit 2, abobotulinumtoxinA was the most frequently injected BoNT-A preparation at both visits (Table 5). The doses of toxin administered to patients according to the injected limbs are shown in Table 5. Overall, the mean (SD) time between injections was 4.6 (0.7) months and using palpation/anatomic landmarks was the most common method used to guide injections. The most frequently injected muscles are reported in Table S3.

Table 5. Drug administration at visits 1 and 2 (FAS) BoNT-A, botulinum toxin type A; FAS, full analysis set; LL, lower limb; n, number of patients; SD, standard deviation, UL, upper limb.

\begin{tabular}{|c|c|c|c|c|c|}
\hline Injection Parameters & AbobotulinumtoxinA & OnabotulinumtoxinA & $\begin{array}{l}\text { Chinese Type } \\
\text { A Botulinum } \\
\text { Toxin }\end{array}$ & $\begin{array}{c}\text { Other } \\
\text { Unspecified } \\
\text { BoNT-A } \\
\text { Preparation }\end{array}$ & Overall \\
\hline $\begin{array}{l}\text { Number of patients } \\
\text { injected at visit 1, } n(\%)\end{array}$ & $173(84.8)$ & $6(2.9)$ & $3(1.5)$ & $22(10.8)$ & $204(100)$ \\
\hline \multicolumn{6}{|c|}{ Dose administered at visit 1 , median (range) units } \\
\hline UL & $600.0(100.0-1500.0)$ & $300.0(190.0-315.0)$ & $\begin{array}{c}205.0 \\
(205.0-360.0)\end{array}$ & $\begin{array}{c}197.5 \\
(37.0-355.0)\end{array}$ & - \\
\hline LL & $450.0(80.0-950.0)$ & $300.0(100.0-350.0)$ & $\begin{array}{c}220.0 \\
(200.0-260.0)\end{array}$ & $\begin{array}{c}56.0 \\
(20.0-400.0)\end{array}$ & - \\
\hline Both limbs & $1000.0(400.0-1904.0)$ & $600.0(300.0-600.0)$ & $\begin{array}{c}425.0 \\
(405.0-620.0)\end{array}$ & $\begin{array}{c}207.5 \\
(99.0-730.0)\end{array}$ & - \\
\hline $\begin{array}{l}\text { Number of muscles } \\
\text { injected at visit } 1, \\
\text { mean (SD) }\end{array}$ & $7.7(3.2)$ & $9.3(1.8)$ & $15.0(1.0)$ & $9.9(2.4)$ & $8.1(3.2)$ \\
\hline
\end{tabular}


Table 5. Cont

\begin{tabular}{|c|c|c|c|c|c|}
\hline Injection Parameters & AbobotulinumtoxinA & OnabotulinumtoxinA & $\begin{array}{c}\text { Chinese Type } \\
\text { A Botulinum } \\
\text { Toxin }\end{array}$ & $\begin{array}{c}\text { Other } \\
\text { Unspecified } \\
\text { BoNT-A } \\
\text { Preparation }\end{array}$ & Overall \\
\hline & \multicolumn{5}{|c|}{ Injection guidance technique used at visit $1, n(\%)$} \\
\hline $\begin{array}{l}\text { Palpation/anatomic } \\
\text { landmarks }\end{array}$ & $156(90.2)$ & $2(33.3)$ & $3(100)$ & $22(100)$ & $183(89.7)$ \\
\hline Electric stimulation & $19(11.0)$ & $4(66.7)$ & 0 & 0 & $23(11.3)$ \\
\hline Echography/ultrasound & 0 & 0 & 0 & $1(4.5)$ & $1(0.5)$ \\
\hline \multirow[t]{2}{*}{$\begin{array}{c}\text { Number of patients } \\
\text { injected at visit } 2, n(\%)\end{array}$} & $170(84.6)$ & $6(3.0)$ & $3(1.5)$ & $22(10.9)$ & $201(100)$ \\
\hline & \multicolumn{5}{|c|}{ Dose administered at visit 2 , median (range) units } \\
\hline UL & $600.0(50.0-1500.0)$ & $307.5(185.0-400.0)$ & $\begin{array}{c}245.0 \\
(201.0-460.0)\end{array}$ & $\begin{array}{c}149.5 \\
(37.0-265.0)\end{array}$ & - \\
\hline LL & $500.0(25.0-1100.0)$ & $237.5(100.0-315.0)$ & $\begin{array}{c}250.0 \\
(190.0-290.0) \\
\end{array}$ & $\begin{array}{c}40.0 \\
(20.0-100.0) \\
\end{array}$ & - \\
\hline Both limbs & $1000.0(175.0-1960.0)$ & $550.0(380.0-600.0)$ & $\begin{array}{c}495.0 \\
(491.0-650.0)\end{array}$ & $\begin{array}{c}180.0 \\
(99.0-275.0)\end{array}$ & - \\
\hline \multirow[t]{2}{*}{$\begin{array}{l}\text { Number of muscles } \\
\text { injected at visit 2, } \\
\text { mean (SD) }\end{array}$} & $7.4(3.4)$ & $9.8(0.8)$ & $14.7(1.5)$ & $8.0(3.0)$ & $7.7(3.4)$ \\
\hline & \multicolumn{5}{|c|}{ Injection guidance technique used at visit $2, n(\%)$} \\
\hline $\begin{array}{l}\text { Palpation/anatomic } \\
\text { landmarks }\end{array}$ & $154(90.6)$ & $3(50.0)$ & $3(100)$ & $22(100)$ & $182(90.5)$ \\
\hline Electric stimulation & $18(10.6)$ & $4(66.7)$ & 0 & 0 & $22(10.9)$ \\
\hline
\end{tabular}

\subsection{Pharmacoeconomic Impact of BoNT-A Injections}

In total, $151(74.0 \%)$ patients required a caregiver, frequently a family member $(n=129,85.4 \%)$, with only $10(6.6 \%)$ patients having a professional caregiver and $12(7.9 \%)$ a combination of caregivers. Family members and professional caregivers dedicated a mean (SD) of 13.2 (8.6) h (median $12.0 \mathrm{~h}$ ) and $11.1(7.3) \mathrm{h}$ (median $10.5 \mathrm{~h}$ ) per day to the patient, ranging from 1 to $24 \mathrm{~h}$. In total, $49.6 \%$ of family members reported that their professional activities were impacted upon by the patient's disease $(n=70 / 141)$.

At baseline, the majority of caregivers responded "a little" or "not at all" in regard to physical or psychological burden relating to their patients' spasticity (Figure S2). The physical burden decreased for $70.2 \%(n=106 / 151)$ of caregivers after cycle 1 and for $63.8 \%(n=83 / 130)$ of caregivers after cycle 2 . In comparison, psychological burden decreased for $56.3 \%(n=85 / 151)$ of caregivers after cycle 1 and for $58.5 \%(n=76 / 130)$ of caregivers after cycle 2 .

\subsection{Safety}

Overall, 46 SAEs (assessed by sponsor) were reported in 15 patients who had been treated with abobotulinumtoxinA throughout the study; 10 of these SAEs were assessed as possibly related to the study drug, as there was insufficient information for a firm causality assessment (Table S4). Of these 15 patients, there were five deaths, which were all considered as unrelated to the study drug. No new safety findings requiring further investigation were identified during the course of the study.

\section{Discussion}

BCause was an observational, non-interventional, post-marketing study designed to investigate the effectiveness of BoNT-A injections in untreated Brazilian patients with chronic post-stroke spasticity. Here, we provide evidence to support the effectiveness of BoNT-A treatment in this patient population, with over half of patients responding after the first cycle $(61.3 \%)$ and second cycle $(56.7 \%)$ of injections indicating the potential benefit of repeat BoNT-A injections in chronic spasticity. The use 
of injection-guiding techniques, e.g., electrical stimulation or ultrasound, is recommended to target BoNT-A injections $[19,20]$. In this study, anatomic palpation was used in approximately $90 \%$ of patients; this reflects the results from Crema et al. (2016), who reported that $80 \%$ of Brazilian medical doctors used muscle palpation techniques and anatomic topographical reference points to guide BoNT-A treatment [21]. Over three-quarters of the patients enrolled in BCause also received physical therapy in addition to BoNT-A injections. In a recent study, Prazeres et al. (2018) reported that BoNT-A injections in combination with physical therapy was superior to physical therapy alone in improving muscle tone in post-stroke spasticity [22].

In comparison to BCause, the ULIS-II study reported that $79.6 \%$ of patients with post-stroke UL spasticity achieved, or overachieved, their primary goal from GAS following a single BoNT-A injection cycle [18]. This result is higher than reported in this study, which could be due to differences in the level of goal-setting experience of investigators between the two studies [18]. In ULIS-II, only $40 \%$ of patients received their first BoNT-A injection within the first year post-stroke, compared with $60 \%$ who received it more than 1 year afterwards [23]. The authors noted that the latter group were older and suggested that younger age could be a trigger for earlier spasticity treatment. Despite this suggestion, the rate of primary goal attainment was similar in both groups ( $80 \% \mathrm{vs.} 79 \%$, respectively), although a greater proportion of goals relating to active function was achieved by those patients with earlier treatment [23].

In the present study, the effectiveness of BoNT-A was also illustrated by an increase in ROM of the shoulder and decrease in pain in the UL at movement. The use of BoNT-A in the reduction of pain and improvement of ROM in the shoulder has been shown in a number of previous studies [24-26], with results from a meta-analysis of randomized controlled trials also reporting that BoNT injections showed more persistent clinical benefits in pain reduction and ROM compared with placebo or steroid injections [27]. The majority $(82.8 \%)$ of patients in the current study presented with an adducted internally rotated shoulder; Gomes et al. (2019) reported similar results in Brazilian patients with post-stroke motor impairment, with $76 \%$ of patients presenting with this pattern of UL spasticity [28]. Improving ROM, motor function, and mobility, and reducing pain are all common goals during rehabilitation post-stroke [29].

The results from the functional independence analyses indicated that patients became more independent throughout the study, with the proportion who could walk independently increasing from $22.8 \%$ to $38.9 \%$, and the mean Barthel Index score increasing throughout the study. Pimental et al. (2014) reported that treatment with $100 \mathrm{U}$ or $300 \mathrm{U}$ of BoNT-A improved $10 \mathrm{~m}$ walking speed in Brazilian patients with post-stroke LL spasticity [30]. Patients in the current study also documented an improvement in their QoL across all EQ-5D-5L domains at each visit, with the mean EQ VAS score increasing from 61.8 to 69.5 between baseline and visit 3 .

The improvement in spasticity symptoms following BoNT-A injections also had a positive impact on caregivers' physical and psychological burden. This result was also seen by Bhakta and colleagues (2000), who reported a reduction in caregiver burden for at least 12 weeks after a single injection of abobotulinumtoxinA compared with placebo in patients with post-stroke UL spasticity [31]. These outcomes can have both direct and indirect economic impacts on the patient's families and country. In the current study, approximately $50 \%$ of family members found that their professional activities were affected by patients' spasticity, and over $60 \%$ of patients reported that their working status was a consequence of their stroke. Therefore, a meaningful increase in independence could reduce some of this burden. The levels of satisfaction reported by patients and caregivers also support this reduction in disease burden, with approximately $44 \%$ of patients and $36 \%$ of caregivers reporting a great benefit after two cycles of BoNT-A injections.

Patients reported a number of environmental and personal factors preventing or delaying their access to treatment; the most frequent issues were the distance or transport to a rehabilitation center and being unable to schedule an appointment. These difficulties may be linked to the public healthcare system in Brazil, since over $90 \%$ of patients had public health insurance. Jorge and colleagues (2015) 
noted that there is a shortage of rehabilitation centers in Brazil, along with inadequate knowledge regarding the need for rehabilitation and poor organization between clinical services and rehabilitation centers [32]. A study assessing factors influencing the functional gain in patients post-stroke in Brazil found that the average time from stroke onset until admission to a rehabilitation program was 8.9 months, which was similar to the median waiting time for an appointment at a center in this study (9.0 months) [33]. Carod-Artal and colleagues (2005) noted that, in patients who started a rehabilitation program at a later stage, functional improvement scores were only approximately $73 \%$ of those for patients who began treatment during the first 6 months [33].

The main limitation of this study was the high dropout rate of patients; this was due to several factors, including shortages of medication and access to the outpatient centers (which was dependent on both transportation and relatives/caregivers). There were no statistical tests performed on the data from the various assessments; therefore, the dropout rate of patients has not been statistically accounted for. The number of enrolled patients was also slightly lower than the sample size target, which was largely due to the limited amount of time available to enroll patients. Despite this limitation, the proportion of patients who achieved their primary goal was higher than expected. The study was also subject to selection bias as it is likely that those who benefitted most from BoNT-A injections would continue until the end of the study. Furthermore, the majority of patients were treated with abobotulinumtoxinA and, therefore, comparisons between the different BoNT-A formulations could not be made.

\section{Conclusions}

In summary, the results from the BCause study provide evidence that BoNT-A is an effective treatment for patients with untreated chronic post-stroke spasticity in both UL and LL, with over half of patients responding to treatment after a single injection. The results suggest that, in situations where early treatment is not possible, such as in countries with a low socioeconomic status, patients can still benefit from BoNT-A treatment provided they are able to access rehabilitation programs.

\section{Methods}

\subsection{Study Design}

BCause was an observational, multicenter, post-marketing, prospective study conducted at 11 centers in Brazil between June 2015 and August 2017.

\subsection{Inclusion and Exclusion Criteria}

Eligible patients were adults, aged 18-80 years, with a last documented stroke (hemorrhagic or ischemic) at least 1 year prior to study entry. All patients had documented UL spasticity, with or without LL spasticity, and must not have received any prior injections of BoNT-A to treat spasticity symptoms. Patients were not eligible to participate if they had undergone previous surgical procedures for spasticity treatment, had received previous phenol injections, or if they may have been indicated to receive phenol during the study. Patients with contraindications to any BoNT-A preparations were excluded.

\subsection{Treatment}

The decision to prescribe BoNT-A was taken prior to, and independently from, the decision to enroll the patient into the study. BoNT-A was prescribed in accordance with routine clinical practice. As this was an observational study, investigators were free to choose the targeted muscles, BoNT-A preparation, injected doses, injection interval, number of injection points, and volume/dosage per point in accordance with local summary of product characteristics and locally agreed therapeutic guidelines.

Patients were treated across two injection cycles: visit 1 (baseline; cycle 1), visit 2 (3-6 months; cycle 1), and visit 3 (6-12 months, cycle 2). Patients received injections of BoNT-A at visits 1 and 2. 


\subsection{Study Assessments and Endpoints}

The primary efficacy endpoint was the responder rate, defined as achievement of the primary goal from the GAS at visit 2 . An agreed set of goals (one primary and $\leq 3$ secondary) was established at visit 1 by identifying the main problem areas and which limbs these related to (UL, LL, or both). Each goal was rated as either "some function" (-1) or "no function" (-2). At visit 2, achievement for each goal was recorded using GAS-Light (a verbal rating scale) [34,35], which was converted to a numerical scale $(-2$, got worse; $-1 /-2$, no change; -0.5 , partially achieved; 0 , as expected; +1 , a little more; +2 , a lot more). Patients were considered as responders if they achieved or overachieved their primary goals at visit 2 (scores $0 /+1 /+2$ ).

Secondary efficacy endpoints assessed the effectiveness of BoNT-A, including the overall attainment of treatment goals using the GAS Total (GAS T) score after each cycle and the overall cumulated GAS T score of all goals assessed during the study. Pain at rest and movement (scored using a visual numeric scale (VNS); from 0 (no pain) to 10 (extreme pain)), ROM using a goniometer at the shoulder level (by measuring the shoulder abduction angle), and Modified Ashworth Scale (MAS) spasticity score (six grades: $0,1,1+, 2,3$, or 4 (for quantitative analyses, grade $1+$ was considered as 1.5) $[9,10,36])$ for UL and LL at each joint, were evaluated at all visits. Functional independence was assessed using the Barthel Index score (ordinal scale used to measure performance in 10 variables describing activities of daily living) at visits 1 and 3 and Functional Ambulation Category (FAC) classification, which organized patients into six categories from level 0 (non-functional) to level 5 (independent), at all study visits. Patients' QoL was also assessed at visits 1, 2 and 3 using the European Quality of Life-5 Dimensions-5 Levels (EQ-5D-5L) questionnaire, where scores were provided using the European Quality of Life Visual Analogue Scale (EQ VAS). Overall satisfaction with treatment effectiveness according to the patient, caregiver, and investigator was assessed at visits 2 and 3 using a 5-point Likert Scale (from "great benefit" to "much worse").

In addition, a number of secondary endpoints described the patient population and treatment practices; these endpoints included any relevant sociodemographic data at visit 1 , and injection practices (e.g., BoNT-A preparation and injection guidance technique). The pharmacoeconomic impact of BoNT-A injections was also assessed at all visits; these included caregiver physical and psychological burden (rated as "not at all", "a little", or "a lot") and the indirect costs of treatment.

This was a non-interventional study in which BoNT-A was administered and managed within routine medical care. Treatment-related adverse events (AEs) and serious AEs (SAEs) were monitored at each study visit and reported to the sponsor's, or the relevant manufacturer's, pharmacovigilance department or marketing authorization holder.

\subsection{Statistical Methods}

Sample size was determined based on the primary efficacy endpoint. Based on a literature review, it was expected that at least $60 \%$ of patients treated with BoNT-A would respond after one cycle of treatment (21). A minimum of 219 patients was needed to achieve a fixed precision of $6.5 \%$ for a 2 -sided $95 \%$ confidence interval (CI) for the expected response rate of $60 \%$, using normal approximation. Assuming a $10 \%$ expected dropout rate, a total number of 244 patients was required.

The full analysis set (FAS) included all patients who received at least one injection of BoNT-A and underwent at least one post-baseline assessment of the primary efficacy parameter. Both primary and secondary endpoints were conducted using the FAS.

The primary endpoint was summarized by the number and percentage of responders overall and per primary goal limbs, together with 2-sided 95\% Agresti-Coull approximate CIs for binomial proportions. For secondary effectiveness endpoints, quantitative summary statistics and/or frequency counts were presented. No statistical analyses of safety data or imputations for missing data were performed. 


\subsection{Ethical Approval}

This study was conducted in compliance with the Declaration of Helsinki, the International Ethical Guidelines for Epidemiological Studies, and all local regulatory requirements applicable to non-interventional studies. The protocol was approved by the Ethics Committee of FAMERP-Instituto de Reabilitação Lucy Montoro (Project identification code: A-38-52120-202) on 10 July 2014. Written informed consent (signed by the participant or his/her legal representative) was provided prior to any study-related procedure.

Supplementary Materials: The following are available online at http://www.mdpi.com/2072-6651/12/12/770/s1, Table S1: (A) MAS in UL joints; (B) MAS in LL joints (FAS), Table S2: Barthel Index score for activities of daily living (FAS), Table S3: Most frequently injected muscles at visits 1 and 2 (FAS), Table S4: Summary of serious adverse events and causality in patients receiving abobotulinumtoxinA, Figure S1: Previous and concomitant therapies: (A) concomitant medications for spasticity $(n=25)$; (B) concomitant non-drug therapies for spasticity $\left(n=181^{\dagger}\right)$, Figure S2: Caregiver's physical and psychological burden at baseline (FAS).

Author Contributions: Conceptualization and design of methodology, P.K.; Methodology, N/A; Software, N/A; Validation, P.M..; Formal analysis, P.M.; Investigation, P.K., M.R., J.A.F., R.C., T.M.C., A.C.F.G.A., D.X., L.H.C.M. A.L.L., S.L.; Resources, N/A; Data curation, P.M.; Writing — original draft preparation and review and editing, P.K., M.R., J.A.F., R.C., A.C.F.G.A., D.X., T.M.C., L.H.C.M., A.L.L., S.L., P.M., V.C.R.-S.; Visualization, N/A; Supervision, V.C.R.-S.; Project administration, V.C.R.-S.; Funding acquisition, N/A. All authors have read and agreed to the published version of the manuscript.

Funding: This study and the APC were funded by Ipsen. Ipsen were involved in the design of the study and decision to publish the results. Ipsen provided funding for medical writing support for this manuscript, and internal stakeholders have reviewed the content prior to publication. Authors who were employees of Ipsen were involved in the design of the study; the analyses and interpretation of data; in the writing of the manuscript, and in the decision to publish the results. Where patient data can be anonymized, Ipsen will share all individual participant data that underlie the results reported in this article with qualified researchers who provide a valid research question. Study documents, such as the study protocol and clinical study report, are not always available. Proposals should be submitted to DataSharing@Ipsen.com and will be assessed by a scientific review board. Data are available beginning 6 months and ending 5 years after publication; after this time, only raw data may be available.

Acknowledgments: The authors thank all patients involved in the study, as well as their caregivers, care team, and all the BCause study investigators and research staff in participating institutions. The authors would also like to thank Thais Cuperman-Pohl, a former employee of Ipsen, for her contributions to the BCause study and during the initial stages of manuscript development. The authors also thank Amy Watkins, of Watermeadow Medical, an Ashfield Company, part of UDG Healthcare plc, for providing medical writing support, which was sponsored by Ipsen in accordance with Good Publication Practice guidelines.

Conflicts of Interest: P.K.: received consultancy fees from Ipsen and Allergan, and honorarium as a speaker from Ipsen and Allergan. M.R.: supported by Ipsen, Allergan and Merz in scientific events as a speaker or participant. J.A.F.: sponsored by Ipsen and Allergan. R.C.: sponsored by Ipsen and Merz in scientific events as a speaker or participant. A.C.F.G.A.: sponsored by Ipsen, Allergan, Merz to attend scientific meetings, and has received funds as an instructor for Dysport. D.X.: received fees from Ipsen and Allergan. T.M.C.: no conflicting interests. L.H.C.M.: supported Ipsen, Allergan and Merz as a speaker for presentations and workshops about botulinum toxin and chemical blockade; sponsored by Ipsen and Merz to attend scientific meetings. A.L.L.: no conflicting interests. S.L.: no conflicting interests. P.M.: employee of Ipsen. V.C.R.-S.: employee of Ipsen at the time this research was carried out.

\section{References}

1. Sommerfeld, D.K.; Eek, E.U.; Svensson, A.K.; Holmqvist, L.W.; von Arbin, M.H. Spasticity after stroke: Its occurrence and association with motor impairments and activity limitations. Stroke 2004, 35, $134-139$. [CrossRef] [PubMed]

2. Watkins, C.L.; Leathley, M.J.; Gregson, J.M.; Moore, A.P.; Smith, T.L.; Sharma, A.K. Prevalence of spasticity post stroke. Clin. Rehabil. 2002, 16, 515-522. [CrossRef] [PubMed]

3. Lundstrom, E.; Terent, A.; Borg, J. Prevalence of disabling spasticity 1 year after first-ever stroke. Eur. J. Neurol. 2008, 15, 533-539. [CrossRef] [PubMed] 
4. Simpson, D.M.; Hallett, M.; Ashman, E.J.; Comella, C.L.; Green, M.W.; Gronseth, G.S.; Armstrong, M.J.; Gloss, D.; Potrebic, S.; Jankovic, J.; et al. Practice guideline update summary: Botulinum neurotoxin for the treatment of blepharospasm, cervical dystonia, adult spasticity, and headache: Report of the Guideline Development Subcommittee of the American Academy of Neurology. Neurology 2016, 86, 1818-1826. [CrossRef]

5. Sheean, G.; Lannin, N.A.; Turner-Stokes, L.; Rawicki, B.; Snow, B.J.; Cerebral Palsy, I. Botulinum toxin assessment, intervention and after-care for upper limb hypertonicity in adults: International consensus statement. Eur. J. Neurol. 2010, 17, 74-93. [CrossRef]

6. Royal College of Physicians. Spasticity in Adults: Management Using Botulinum Toxin. National guidelines 2018. Available online: https://www.rcplondon.ac.uk/guidelines-policy/spasticity-adults-managementusing-botulinum-toxin (accessed on 5 June 2018).

7. Dashtipour, K.C.; Walker, H.W.; Lee, M.Y. Systematic literature review of abobotulinumtoxinA in clinical trials for adult upper limb spasticity. Am. J. Phys. Med. Rehabil. 2015, 94, 229-238. [CrossRef]

8. Dashtipour, K.; Chen, J.J.; Walker, H.W.; Lee, M.Y. Systematic literature review of abobotulinumtoxinA in clinical trials for lower limb spasticity. Medicine 2016, 95, e2468. [CrossRef]

9. Gracies, J.-M.; Esquenazi, A.; Brashear, A.; Banach, M.; Kocer, S.; Jech, R.; Khatkova, S.; Benetin, J.; Vecchio, M.; McAllister, P.; et al. Efficacy and safety of abobotulinumtoxinA in spastic lower limb: Randomized trial and extension. Neurology 2017, 89, 2245-2253. [CrossRef]

10. Gracies, J.M.; Brashear, A.; Jech, R.; McAllister, P.; Banach, M.; Valkovic, P.; Walker, H.; Marciniak, C.; Deltombe, T.; Skoromets, A.; et al. Safety and efficacy of abobotulinumtoxinA for hemiparesis in adults with upper limb spasticity after stroke or traumatic brain injury: A double-blind randomised controlled trial. Lancet Neurol. 2015, 14, 992-1001. [CrossRef]

11. Cardoso, E.; Rodrigues, B.; Lucena, R.; Oliveira, I.R.; Pedreira, G.; Melo, A. Botulinum toxin type A for the treatment of the upper limb spasticity after stroke: A meta-analysis. Arq. Neuro-Psiquiatr. 2005, 63, 30-33. [CrossRef]

12. ANVISA-AGÊNCIA NACIONAL DE VIGILÂNCIA SANITÁRIA. Detalhe do Produto: BOTOX. Available online: https://consultas.anvisa.gov.br/\#/medicamentos/250000055089118/ (accessed on 3 February 2020).

13. Hesse, S.; Mach, H.; Frohlich, S.; Behrend, S.; Werner, C.; Melzer, I. An early botulinum toxin A treatment in subacute stroke patients may prevent a disabling finger flexor stiffness six months later: A randomized controlled trial. Clin. Rehabil. 2012, 26, 237-245. [CrossRef] [PubMed]

14. Rosales, R.L.; Kong, K.H.; Goh, K.J.; Kumthornthip, W.; Mok, V.C.; Delgado-De Los Santos, M.M.; Chua, K.S.; Abdullah, S.J.; Zakine, B.; Maisonobe, P.; et al. Botulinum toxin injection for hypertonicity of the upper extremity within 12 weeks after stroke: A randomized controlled trial. Neurorehabil. Neural. Repair. 2012, 26, 812-821. [CrossRef] [PubMed]

15. Tao, W.; Yan, D.; Li, J.-H.; Shi, Z.-H. Gait improvement by low-dose botulinum toxin A injection treatment of the lower limbs in subacute stroke patients. J. Phys. Ther. Sci. 2015, 27, 759-762. [CrossRef] [PubMed]

16. Kong, K.H.; Balcaitiene, J.; Berard, H.; Maisonobe, P.; Goh, K.J.; Kumthornthip, W.; Rosales, R.L. Effect of early use of AbobotulinumtoxinA after stroke on spasticity progression: Protocol for a randomised controlled pilot study in adult subjects with moderate to severe upper limb spasticity (ONTIME pilot). Contemp. Clin. Trials Commun. 2017, 6, 9-16. [CrossRef] [PubMed]

17. Yan, L.L.; Li, C.; Chen, J.; Miranda, J.J.; Luo, R.; Bettger, J.; Zhu, Y.; Feigin, V.; O’Donnell, M.; Zhao, D.; et al. Prevention, management, and rehabilitation of stroke in low- and middle-income countries. eNeurologicalScience 2016, 2, 21-30. [CrossRef] [PubMed]

18. Kiresuk, T.J.; Sherman, R.E. Goal attainment scaling: A general method for evaluating comprehensive community mental health programs. Community Ment. Health J. 1968, 4, 443-453. [CrossRef]

19. Ipsen Biopharm Ltd. Dysport Full Prescribing Information. Available online: https: //www.ipsen.com/websites/Ipsen_Online/wp-content/uploads/sites/9/2020/01/09195739/S115_2019_ 09_25_sBLA_Approval_PMR_Fulfilled_PI_MG_Sept-2019.pdf (accessed on 26 February 2020).

20. Allergan, Inc. Highlights of Prescribing Information: Botox@. Available online: https://www.accessdata.fda. gov/drugsatfda_docs/label/2017/103000s53021bl.pdf (accessed on 14 August 2018).

21. Crema, C.M.T.; Santos, A.P.B.C.; Magário, L.P.T.; Caldas, C.A.C.T.; Riberto, M. Neuromuscular block practice in the treatment of spasticity in Brazil. Physiatr. Act. 2016, 23, 150-154. [CrossRef] 
22. Prazeres, A.; Lira, M.; Aguiar, P.; Monteiro, L.; Vilasboas, I.; Melo, A. Efficacy of physical therapy associated with botulinum toxin type A on functional performance in post-stroke spasticity: A randomized, double-blinded, placebo-controlled trial. Neurol. Int. 2018, 10, 7385. [CrossRef] [PubMed]

23. Fheodoroff, K.; Ashford, S.; Jacinto, J.; Maisonobe, P.; Balcaitiene, J.; Turner-Stokes, L. Factors influencing goal attainment in patients with post-stroke upper limb spasticity following treatment with botulinum toxin A in real-life clinical practice: Sub-analyses from the Upper Limb International Spasticity (ULIS)-II Study. Toxins 2015, 7, 1192-1205. [CrossRef] [PubMed]

24. Marco, E.; Duarte, E.; Vila, J.; Tejero, M.; Guillen, A.; Boza, R.; Escalada, F.; Espadaler, J.M. Is botulinum toxin type A effective in the treatment of spastic shoulder pain in patients after stroke? A double-blind randomized clinical trial. J. Rehabil. Med. 2007, 39, 440-447. [CrossRef] [PubMed]

25. Yelnik, A.P.; Colle, F.M.; Bonan, I.V.; Vicaut, E. Treatment of shoulder pain in spastic hemiplegia by reducing spasticity of the subscapular muscle: A randomised, double blind, placebo controlled study of botulinum toxin A. J. Neurol. Neurosurg. Psychiatry 2007, 78, 845-848. [CrossRef] [PubMed]

26. Pedreira, G.; Cardoso, E.; Melo, A. Botulinum toxin type A for refractory post-stroke shoulder pain. Arq. Neuro-Psiquiatr. 2008, 66, 213-215. [CrossRef] [PubMed]

27. Wu, T.; Fu, Y.; Song, H.X.; Ye, Y.; Dong, Y.; Li, J.H. Effectiveness of Botulinum Toxin for Shoulder Pain Treatment: A Systematic Review and Meta-Analysis. Arch. Phys. Med. Rehabil. 2015, 96, 2214-2220. [CrossRef]

28. Gomes, A.L.S.; Mello, F.F.; Cocicov Neto, J.; Benedeti, M.C.; Modolo, L.F.M.; Riberto, M. Can the positions of the spastic upper limb in stroke survivors help muscle choice for botulinum toxin injections? Arq. Neuro-Psiquiatr. 2019, 77, 568-573. [CrossRef]

29. Francisco, G.E.; McGuire, J.R. Poststroke spasticity management. Stroke 2012, 43, 3132-3136. [CrossRef]

30. Pimentel, L.H.; Alencar, F.J.; Rodrigues, L.R.; Sousa, F.C.; Teles, J.B. Effects of botulinum toxin type A for spastic foot in post-stroke patients enrolled in a rehabilitation program. Arq. Neuro-Psiquiatr. 2014, 72, $28-32$. [CrossRef]

31. Bhakta, B.B.; Cozens, J.A.; Chamberlain, M.A.; Bamford, J.M. Impact of botulinum toxin type A on disability and carer burden due to arm spasticity after stroke: A randomised double blind placebo controlled trial. J. Neurol. Neurosurg Psychiatry 2000, 69, 217-221. [CrossRef]

32. Jorge, L.L.; de Brito, A.M.d.N.; Marchi, F.H.G.; Hara, A.C.P.; Battistella, L.R.; Riberto, M. New rehabilitation models for neurologic inpatients in Brazil. Disabil Rehabil. 2015, 37, 268-273. [CrossRef] [PubMed]

33. Carod-Artal, F.J.; Medeiros, M.S.; Horan, T.A.; Braga, L.W. Predictive factors of functional gain in long-term stroke survivors admitted to a rehabilitation programme. Brain Inj. 2005, 19, 667-673. [CrossRef] [PubMed]

34. Turner-Stokes, L. Goal attainment scaling (GAS) in rehabilitation: A practical guide. Clin. Rehabil. 2009, 23, 362-370. [CrossRef]

35. Turner-Stokes, L.; Fheodoroff, K.; Jacinto, J.; Maisonobe, P.; Zakine, B. Upper limb international spasticity study: Rationale and protocol for a large, international, multicentre prospective cohort study investigating management and goal attainment following treatment with botulinum toxin A in real-life clinical practice. BMJ Open. 2013, 3, e002230. [CrossRef]

36. Turner-Stokes, L.; Fheodoroff, K.; Jacinto, J.; Maisonobe, P. Results from the Upper Limb International Spasticity Study-II (ULISII): A large, international, prospective cohort study investigating practice and goal attainment following treatment with botulinum toxin A in real-life clinical management. BMJ Open. 2013, 3, e002771. [CrossRef]

Publisher's Note: MDPI stays neutral with regard to jurisdictional claims in published maps and institutional affiliations.

(C) 2020 by the authors. Licensee MDPI, Basel, Switzerland. This article is an open access article distributed under the terms and conditions of the Creative Commons Attribution (CC BY) license (http://creativecommons.org/licenses/by/4.0/). 